\title{
Is There any Connection between Academic Performance, Locus of Control and Learning Styles?
}

\author{
Phd. Artemisi Shehu* \\ Msc Nevina Bushi* \\ *Tirana University, Faculty of Social Sciences, Department of Psychology and Education \\ Email: art_emisa@yahoo.com
}

\author{
Doi:10.5901/ajis.2015.v4n2s2p188
}

\begin{abstract}
The personality of a person is a mistery and full of labirinths and part of all this is even the locus of control, which is a crucial part of someone's personality, as well as the style that he chooses to process the given information. Both of these are factors that have a significant impact on individual lives and this was a very strong motive why it is chosen to handle the impact of locus and learning styles in academic performance. To see how influential is locus of control and learning style in academic performance we are based in theories of foreign authors and applying test J.Rooter to understand students' locus of control and that of Kolb's to discover the style with which a student learns by comparing these two with the academic performance for which was not chosen any specific measuring tool, is used only the average grade student. Target group taken in the study are students from nine 9-years-old schools from the city of Tirana, are 486 students participated, the seven, the eighth and the ninth classes, where are taken 3 classes for each paralel, which means in total there are 57 schools in the study that are chosen in a random way. Results showed that learning style as well as locus of control has no impact on academic performance, which means that if a student has a low average or higher, not at all influenced by external or internal locus of control that he may have and, not less influenced by style imaginative, enthusiastic, logical or practical learning. The impact of locus of control and academic performance style is mentioned very little in different studies, so it is recommended to increase knowledge of these areas, so is necessary that other authors to do more researchs reguarding to this topic. Also, is recommended training in this area to sensitize and inform staff working with students ranging from teachers to parents and school psychologists and school management staff.
\end{abstract}

Keywords: locus of control, academic performance, learning style.

\section{Introduction}

The field of study on academic performance of the students is very wide one. Nowadays researchers are paying more attention to factors that may lead to the promotion or inhibition of the academic performance, which seem to be a lot. There are many studies done on these factors and ways how they affect the academic performance of students. These studies have given their contribution in exploring ways how to work with students so that they can have a much higher performance and succes.

Often, the observations during the practice in school contexts have observed that the various students choose different ways to receive and process the information that are served by their teachers, or students who attribute their performances of learning to the faith, fate or random coincidence, while others believe that their behavior is governed by their thoughts and personal efforts (ex: Shultz \& Shultz, 2005). But other studies show that neither the learning style nor type of locus of control does affect academic performance (ex: Dunn, Beaudry, \& Klavas, 1998).

Various researchers (Roddenberry et al., 2002) have concluded that the locus of control and learning style are two of many factors that affect the academic performance of students of 9-year schools. This is a very important field, with a big importance to research field, because the results that may arise from such studies may be necessary to increase the academic performance of students.

Which is kind of locus of control and the best style of learning that will lead to a higher academic performance? But rather than be given an answer to this question we must see how these factors affect one another and then what is the relationship that may exist between them and academic performance.

The concept 'learning style' is a phizical or permanent model of how a person receives and processes knowledge in different situations of life (Coffield et al., 2004, www. jasonswrench.com). 
A key concept is the one that people are different in how they learn throught learning procedure throughout their lives. The concpet of 'individualized learning styles' originated from 1970 to 1979 and has made a great contribute to the wide field of science of learning (Barbe \& Milone, 1979, answerparty.com).

Supporters of learning styles in education considered that teachers should assess learning styles of their students and adapt their methods to the pupils in the class (Curry, 1990). There exist a wide evidence for differences in individual thinking and ways of processing different types of information (Stahl, 2002).

Kolb's model is founded on experiential learning theory. According to Kolb's model, ideal learning process is dedicated to these four ways in response to the demands of the situation. In order for learning to be effective, all four of these styles should be combined. These learning styles that he explaines are: Enthusiastic: Concrete Experience plus Active Experimentation (person is concrete, wants to do things himselves, set goals, asks questions without fear, is adaptable and decides feelings instead of logic); practical style: abstract conceptualisation plus active experimentation (the person is theoretical, uses analogies, works alone and tends to solve problems); imaginative style: concrete experience plus observation reflective (person focuses on the reality, gives different solutions, works through the technique of brainstorming and teamwork and prefers alternatives); and logical style: plus reflective observation abstract conceptualization (person prefers the theory and facts, patterns and graphs, speaking more than makes, significant lectures, problem sets) (Kolb, 1985; www.answerparty.com).

Learning styles have been developed and studied even by other authors such as Peter Honey and Alan Mumford, based on the work of Kolb. They have identified four other learning styles: activist, theorist; reflectiv and pragmatist (Honey \& Mumford, 2006; www.google.co.uk).

Another survey by Honey didn't show specific styles of learning, eventhought he concluded that: "Imaginative" (those who have an open-minded approach to learning) will have a faster pace in making things, in a shorter time compared with Enthusiasts' (those who doesn't want to proceed). He noticed that imaginatives may have more difficulty to motivate themselves than "theorists" (those who like to analyze the information and withdraw from new one) and "practice" (those who like to try and test the new information) (Honey \& Mumford, 2006; www.ittralee.ie).

In summary, it can be said that learning style is connected with the way an individual chooses to process the received information and in this case we can understand how students learn especially in the primary and middle schools years.

According to Rotter, 'Locus of control' as a concept refers to the level, in which someone feels to control the contexts that sorrund him (Rotter, 1966; www.answers.com). Individuals with a high level of internal locus of control believe that everything that happens, is a consequence from their doings. Those who have a high level of external locus of control mostly believe that the close people, fate or chance decide their fate. Individuals with high internal locus of control have a better control over their behavior, than those with external locus, and are inclined to influence others more. It is very likely that those who believe that their efforts will be successful (Lefcourt, 1982; www.uir.unisa.ac.za). The concept of locus of control was studied initially by Rotter by 1950. It refers to the perception of someone on the issues and events of life. Rotter created a bridge between cognitive psychology and the behavioral. Rotter widely observed that the behavior was led by "reinforcements" (repetition and punishment) and on the basis of their people begin to believe that it was caused by their actions and by that depend on the consequences of these actions (Rotter, 1966; www.uir.unisa.ac.za).

In general, internal locus seems psychologically healthier for a person just to have things his control and to be able to influence others.

The studies showed that pupils with internal locus of control had the best results in academic performance as well as in social relations (ex: Chuah, Chong \& Cheng, 1988). It was assumed for a long time how with age, people will become the locus of control to lower domestic and external locus highest or vice versa, but the data are ambivalent. Researches guided by Gatz and Karel (Parnickey et al., 2004) and Lachman claim that locus of control is unclear. Evidence cited by Schultz and Schultz (2005) suggest that the growth of internal locus of control may grow in older age. These researchers suggested that efforts to control the surrounding may be more distinctive between 8 and 14th years old. Pupils which have an internal locus have a more elevated selfvalue in comparison with those pupils with external locus of control (Maltby, Day, Macaskill, 2007; www.answers.com).

Studies also show that people with internal locus of control this fact may influence his performances and skills (Lefcourt, 1966). Someone that has expetations of succes will be more motivated to learn.

Another study showed that internal locus pupils' will show higher performance academic and social relations (Sandler \& Lakey, 1987). Dates gathered by Kernis, Grannemann and Barclay show that the locus of control has a negative correlation with the withdrawal from school and school failure (Kernis, Grannemann, \& Barclay, 1989; 
www.uir.unisa.ac.za).

By the other hand, Rotter hypothesized upon a relationship between locus of control and school results. He theorized that people with internal locus have greater performance than those who feel they have less control over the situation. Rotter has made this study with students discovering that these two variables affect each-other. Individuals with internal locus are more motivated by the attribution to do you. Consequently academic results are higher. Studies on this issue have continued all these years to students of all educational levels, which have confirmed this link (Rotter, 1975; www.uir.unisa.ac.za).

Academic performance is the result of knowledge - the degree to which someone has realized learning goals. The measure of academic performance is very long being debated because there exist different way of assessments (www.oppapers.com).

Studies show that students with a high academic performance have an internal locus of control, and vice versa those students with low academic performance have an external locus of control. This thing shows a study by S. Shephered, D. Owen, TJ.Fitch and JL.Marshall to 187 students of 8th grade at a school in America (Shephered, et al., 2006; Rahmani, 2012).

On the other hand, it is necessary to give importance to learning levels in order to carry out the period of active learning. Citing learning, in addition to behavioral changes and recognition, one or more of the following situations are accepted to be enough (Eisner, 1997).

Learning can be described as a series of learning experiences. Learning can sometimes be only a transfer of information and the way that contributes to the student's emotional and social development (Keefe \& Jenkins, 1997).

Other studies have been made upon locus of control in relation to academic results. A recent study by Furnham and Steele has confirmed this observation and noted the significant differences between high academic performance and locus of control. Other studies showed that there is a connection between learning styles and academic performance (Furnham \& Steele, 1993).

So it can be concluded that there are different studies and researches that show different conclusions to the relationship between academic performance, locus of control and learning styles.

\section{Methods}

The purpose of this research is the discovery of the correlation among learning styles, locus of control and academic performance in pupils in middle school years.

Many studies (example Dunn et al, 1989) have shown that students with an internal locus of control have shown high academic performance and social relations. So, students who have external locus of control might be those who withdraw from school and fail their studies.

Studies show that students with a high academic performance have an internal locus of control, and vice versa those students with low academic performance have an external locus of control (Hsia, Jung-Wen, Chia-Chi Chang, \& AiHua Tseng, 2014). This thing shows a study by Shephered, Owen, Fitch and Marshall to 187 students of 8th grade at a school in America mentioned even above.

A second goal is the discovery of the correlation between learning styles and locus of control.

The hypothesis that this study raises, are:

Hypothesis 1: It is expected to be no connection between learning style and locus of control.

From various studies it has been observed that those students who have a learning styles where they learn more easily reach by viewing things, listening to learning have a higher academic performance compared with their other friends who may have another learning style, it also shows a study by Xenikou and colleagues of 200 students from the 7th, 8th, 9th (Xenikou, Furnham, \& Mccarrey, 1997).

Hypothesis 2: It is expected to be no connection between learning styles and academic performance. From various studies it has been observed that those students who have a learning style where they learn more easily reach by viewing things, listening to learning have a higher academic performance compared with their other friends, who may have another learning styles, this also shows a study by Xenikoe and colleagues to 200 students from the 7 th, 8th, $9^{\text {th }}$ (Xenikou, Furnham \& McCarrey, 1997).

Hypothesis 3: It is expected to be no connection among gender and someone's learning styles.

People differentiate in academic performance have been associated with changes in intelligence and personality. Students with high mental skills and high scores on the conscience (associated with effort and motivation) tend to achieve more in academic environments. While seeing the students as equal number as those men and women thought that there 
would be no significant differences between them in the context of academic performance (Keefe, 1979).

Hypothesis 4: It is expected to be no connection between locus of control and academic performance.

Hypothesis 5: It is expected to be no link between locus of control and gender.

The study sample was chosen randomly. The instruments are used for the realization of this study, are: questionnaire of Kolb's about learning styles (this questionnaire is composed of 40 questions. Questions have two alternatives 'agree' or 'disagree') (Kolb, 1984) and Rotter questionnaire for locus of control (Rotter, 1990). The degree of control of Rotter locus consists of 29 questions about the locus of control measure determining whether the individual has a locus control internal or external. The test contains 29 questions that sought to qarkohej answer that they fit better. Efficiency of questions is very high because of testuarit surrounding alternative they prefer, but without knowing how to evaluate their response. The test evaluates the tendency of level of locus of control.

Data analysis was made by SPSS 20, where this program was used some of the methods he offers as Pearson correlation (Pearson Correlation) to make the necessary correlations in the study, which was used ANOVA for find links between variables which are composed of them more than two groups, and T-test was used to detect links between variables which are made up into two groups.

The sample selected for the realization of this study consists of 486 9-year school students, of whom 281 are women and 204 men. The study was conducted in nine schools in the capital. The schools were selected at random, from the total of 57 schools in the city of Tirana. There were choosen the clases of the 7, 8 and 9 grade and from each school were three parallel classes A, B, and C. In these nine classes were selected 6 students per class. They were selected randomly from the database with the numbers $1,6,11,16,21,26$. And if the student were absent, it would deal the next present number.

The study respected the ethical issues, which are related to: informed consent of the participants, respect for confidentiality and the avoidance of fraud, disclosure of data, etc.

The manner of implementation of the study together with its components has advantages and disadvantages, but the methodology selected remains the most optimal option to perform this study. However each methodology has its critics.

One of the shortcomings of the study is the lack of the use of more instruments and the short time available to deal with the data of the study.

Among the strengths can be mentioned significant number of samples, broad scope of representation in the capital's schools.

\section{Results and discussion}

To measure the academic performance of students was used overall average grades of each student. It was grouped in such groups: 5-6, where the average was 91 students (18.80), 6.1-7 which had 103 students (21:28\%), 7.1-8 which had 112 students (23:14\%), 8.1- 9 which had 97 students (20.04\%), and 9.1-10 that had 81 students (16.74\%). Thus it can be said that in general there was an average level of students, given that the largest number of them constitute averages average 7.1-8.

It was taken the students that studid the seventh, eighth and ninth grade which consisted of students who were aged 12-16 years. And more specifically there are: 48 students who were 12 years of age who make up $9.88 \%$ of the sample, 121 students (24.90\%) 13, 172 students (35.39\%) aged 14 years, 134 students (27.57\%) 15 years, and only 11 students aged 16 who accounted for $26.2 \%$ of all students.

As regards the data on learning styles were used average, medial, standard deviation, minimum and maximum number of questions that were used to establish each style: logical style had average 6.3711 , medial 6.0000, 1.45681 standard deviation, maximum and minimum value 2:00 10:00. Practical style have average 7.0000, medial 7.0000, 1.48825 standard deviation, maximum value and minimum 10:00 2.00 enthusiastic style of learning we mean 8.4318, medial 5.0000, 1.92459 standard deviation, minimum and maximum value 2:00 10:00 and style imaginative learning have average 5.0680, medial 9.0000, 1.74381 standard deviation, minimum and maximum value 2:00 10:00.

The link between learning style and locus of control: to understand whether there is a correlation between these two variables that we will have to look at the connection among locus of control with each learning styles, so it can then be a general conclusion. 


\section{Correlation}

\begin{tabular}{|ll|c|c|}
\hline & Locus of control & Practical \\
\hline Locus of control & Pearson correlationi & 1 & .045 \\
& Sig. (2-tailed) P & & .321 \\
& $\mathrm{~N}$ & 485 & 485 \\
\hline Practical Style & Pearson correlationi & .045 & 1 \\
& Sig. (2-tailed) P & .321 & \\
& $\mathrm{~N}$ & 485 & 485 \\
\hline
\end{tabular}

The table shows the correlation of locus of control and Practical learning style, where as it exists a sort of correlation among the two, because $p<0: 05$, in this case $p=0321$ means that we don't have a strong correlation between these two variables.

\section{Correlation}

\begin{tabular}{|ll|c|c|}
\hline & Locus of control & Imaginative \\
\hline Locus of control & Pearson correlationi & 1 & $.106^{*}$ \\
& Sig. (2-tailed) P & & .020 \\
& $\mathrm{~N}$ & 485 & 485 \\
\hline Imaginative & Pearson correlationi & $.106^{*}$ & 1 \\
& Sig. (2-tailed) P & .020 & \\
& $\mathrm{~N}$ & 485 & 485 \\
\hline
\end{tabular}

This chart shows the correlation among locus of control and imaginative style of learning, where $P=0.020$ which means that there is a statistically significant correlation among these two variables.

\begin{tabular}{|ll|c|c|}
\multicolumn{2}{|c|}{ Correlation } \\
\hline Locus of control & Locus of control & Enthusiastic \\
& Pearson correlationi & 1 & $-.119^{+*}$ \\
& Sig. (2-tailed) P & & .009 \\
& $\mathrm{~N}$ & 485 & 484 \\
\hline Enthusiastic & Pearson correlationi & $-.119^{\text {** }}$ & 1 \\
& Sig. (2-tailed) P & .009 & \\
& $\mathrm{~N}$ & 484 & 484 \\
\hline
\end{tabular}

The link between locus of control and enthusiastic style of learning, which have $P=0.009$ between them, means that there is no statistically significant correlation between them. So no correlation is seen among locus of control and enthusiastic style.

\begin{tabular}{|ll|c|c|}
\hline \multicolumn{2}{|c|}{ Correlation } \\
\hline \multirow{4}{*}{ Locus of control } & Locus of control & Logical \\
& Pearson correlationi & 1 & -.054 \\
& Sig. (2-tailed) P & & .235 \\
& $\mathrm{~N}$ & 485 & 485 \\
\hline Logical & Pearson correlationi & -.054 & 1 \\
& Sig. (2-tailed) P & .235 & \\
& $\mathrm{~N}$ & 485 & 485 \\
\hline
\end{tabular}

The link between locus of control and logical style of learning, where as shown in the table have a negative correlation between the two, and $\mathrm{P}=0.235$, which means that we have a significant statistical correlation between the two.

Finally, about the relationship among these two variables it can be said that there is a connection between them, given that both (he enthusiastic and imaginative style) learning styles correlated with locus of control while two others not (it logical and practical one). So there is a statistically significant relationship among these two variables and partially thrown down the first hypothesis, which asserted: there is no connection among these two variables. Which means that 
locus of control of a student depends on his style and vice versa learning style of the student learning is influenced by his locus of control.

As regards the connection between learning style and academic performance have these data for the correlation between logical style of Learning and Academic Performance, which in the case of this study will be measured by the average of the students. This correlation has been studied by ANOVA test. Where as can be seen from the table in the beginning provided some general information about the number of students for each of the averages, where the dominant group is the average 7.1-8, where the average was 113 students, while 91 of them they average 5-6, 102 had annual average growth rate 6.1-7, 8.1-9 average 97 and 81 of them average 9.1-10.

ANOVA

\begin{tabular}{|l|c|c|c|c|c|}
\hline & Mean & df & Mean & F & Sig. \\
\hline Intermediate variance & 7.200 & 4 & 1.800 & .846 & .497 \\
Internal variance & 1019.599 & 479 & 2.129 & & \\
Total variance & 1026.800 & 483 & & & \\
\hline
\end{tabular}

The data between logical style and academic performance was noted that $p=0497$, which means that there is a significant correlation between Academic Performance and logic learning style, because $\mathrm{P}=0497$.

Regarding practical learning style and academic performance records give us a weak correlation between them. It is this correlation is $p=0067$ which means that there is a statistically significant link between style Practical Learning and Academic performance.

Data between imaginative style and academic performance shows that the correlation between Academic Performance and Learning imaginative style is $p=0.749$ which means that there is no correlation between these two variables.

Enthusiastic style of learning and academic performance shows that we have a correlation Anova $p=0244$ which means that there is no significant correlation between the style enthusiastic Learning and Academic performance.

In conclusion, it is noticed no correlation between learning styles and Academic performance, which in this case is measured by the average of the students. So two of our study hypotheses are accepted, since it states that: It is expected to be no link among learning styles and academic performance.

The data show the correlation between locus of control and academic performance, the latter measured by the average student. By ANOVA on the link coefficient locus of control and academic performance is noted that to see whether or not there is such a connection is using ANOVA test. Since $P=0318$ means that there is a significant link among locus of control and academic perfomance.

Finally it can be said that locus of control is not affected by academic student performance.

Regarding the relationship between locus of control, learning style and gender to see this connection is used T test. While this information extracted from the $\mathrm{t}$ - test, we will Q. Where CONCERN value will initially see the link between locus of control and gender, $P=0372$, ie $P>0.0 d$ which means that there is no important difference among locus of control and gender. This means that the hypothesis 5 is accepted.

Also, these data give us the connection between each gender and learning style, where we first logical learning style and gender, where $\mathrm{P}=0033$, then $\mathrm{P}<0: 05$ which mean that there is a statistically significant link between logical learning style and gender.

Then we have the practical style of learning and gender, where $P=0294$ which means that there is no statistically significant connection between practical learning style and gender, because $p>0.05$. Subsequently, it is imaginative style of learning and gender, where $p=0563$ which means that there is no significant connection between these two variables. And finally, is Enthusiastic learning style and gender, where $p=0.001$ which means that it is seen a statistically significant connection between this style of learning and gender.

In conclusion, we can say that there is a statistically significant connection between Learning Styles and gender, because in two of the cases (to the style it logical and enthusiastic) statistically have a meaningful connection between them and gender, while in two cases other (to practical and imaginative style) have no significant connection between learning style and gender. So, the third hypothesis swoops. So we can say that: the style of learning that a student is influenced by their gender, although the differences are not very large, however, the results shows that women are the ones that are dominating these learning styles: logical, practical and enthusiastic, while men generally have an imaginative style of learning. 


\section{Conclusions}

From the obtained data analysis of the questionnaires we come to some conclusions:

Learning style of students is affected by the locus of control. But this is true only for imaginative and enthusiastic learning styles, and logical and practical learning styles this assertion is not true. And conversely the type of control locus is influenced by the learning style only to those students who have an imaginative and enthusiastic learning style.

The type of learning style does not affect academic performance and vice versa academic performance that a student does not affect the type of his style of learning. So if a student has average high, medium or low grades, this does not have anything to do with his style of learning.

Boys generally longer apply their own style of learning, having an imaginative style of learning, while the girls this style varies in the other three kinds of practical, logical and enthusiastic.

Locus of control may be a student, it does not affect the academic performance can be an apprentice.

Locus of control of the student has no connection to his gender. So it can not be a definitive separation between the locus of control and gender, since both women and men can have an individual locus of control.

Whether a student was born in the capital, or in other districts of the country or abroad, this does not affect his locus of control, learning style or academic performance.

\section{Recommendations}

Results and conclusions drawn from this study give us the opportunity to make some recommendations:

There is important to put more importance to the locus of control and emphasize it as we emphasize the motivation, intelligence, because it is an important quality of human personality that impacts the success or failure of a student and his academic results. It is good that teachers and those who work with the students know one's locus of control.

Teachers must be given the opportunity to recognize learning styles of students: by training them through different workshops, etc. The recognition of learning style helps in finding new ways to teach better and give the given information in the proper individual learning style. As well it mght improve learning abilities.

For researchers it is recommended to test the hypothesis in a greater target of students and to conduct the research in other age students as well.

\section{Reference}

Barbe, W, B., Swassing, R, H., Milone, M. N., (June 1979). Teaching Through Modality Strengths: Concepts and Practices. Columbus, Ohio: Zaner-Blosner.

Chuah, Ch., Chong, L., Cheng, W., 1988, "Social Learning Theory of Julian B. Rotter" Archived from the original 2012-04-07 http://versys.uitm.edu.my/prisma/view/viewPdf.php?pid=50126

Coffield, F., Moseley, D., Hall, E., Ecclestone, K. (2004). Learning styles and pedagogy in post-16 learning. A systematic and critical review. London: Learning and Skills Research Centre

Curry, L. (1990). "One critique of the research on learning styles". Educational Leadership 48: 50-56

Dunn, B., Beaudry, R., \& Klavas, M., 1989, Journal of Reading, Writing, and Learning Disabilities International Volume 6, Issue 3, 1990 http://www.tandfonline.com/doi/abs/10.1080/0748763900060301?journalCode=urwl19

Eisner, J.E. (1997). "The origins of explanatory style: Trust as a determinant of pessimism and optimism". In Buchanan, G.M., Seligman, M.E.P. Explanatory Style. NJ: Lawrence Erlbaum Associates. pp. 49-55.

Fini, A. A. Sh., and Yousefzadeh, Mitra., "Survey on Relationship of Performance Motivation, Locus of Control and Academic Performance in High School Students of Bandar Abbas (Iran)", Procedia - Social and Behavioral Sciences, 2011.

Furnham, A., Steele, H. (1993). "Measures of Locus of Control: A critique of children's, health and work-related locus of control questionnaires". British Journal of Psychology 84 (4): 443-79.

Garner-O'Neale, Leah D, and Faith Brooks. "The Index of Learning Styles as Predictors of Cave Hill Undergraduate Chemistry Students' Performance in Inorganic Chemistry", Academic Journal of Interdisciplinary Studies, 2013.

Lefcourt, H. M., Locus of Control: Current Trends in Thory and Research. Psychology Press, 1982.

Honey, P \& Mumford, A (2006). The Learning Styles Questionnaire, 80-item version. Maidenhead, UK, Peter Honey Publications.

Hsia, Jung-Wen, Chia-Chi Chang, and Ai-Hua Tseng. "Effects of individuals' locus of control and computer self-efficacy on their elearning acceptance in high-tech companies", Behaviour and Information Technology, 2014.

Inozu, M., Orcun, Y., and Terzi, S, "Locus of Control in Obsessive-Compulsive (OC) and Depression Symptoms: The Moderating Effect of Externality on Obsessive-Related Control Beliefs in OC Symptoms", Behaviour Change, 2012.

Keefe, J. W. (1979). Learning style: An overview. In Student learning styles - Diagnosing and prescribing programs. Reston, VA: 
National Association of Secondary School Principals.

Keefe, J. W., \& Jenkins, J. M. (1997). Instruction and the learning environment. Larchmont, NY: Eye on Education.

Kernis, M., Grannemann, B., \& Barclay, L. (1989): Stability and level of self-esteem as predictors of anger arousal and hostility. Journal of Personality and Social Psychology, 56, 1013-1022.

Kolb, David (1984). Experiential learning: Experience as the source of learning and development. Englewood Cliffs, NJ: Prentice-Hall.

Kolb, D. (1985). Learning Style Inventory: Self Scoring Inventory and Interpretation Booklet. Boston, MA: McBer \& Company.

Lefcourt, H.M. (1966). "Internal versus external control of reinforcement: A review". Psychological Bulletin 65 (4): 206-20.

Maltby, J., Day, L., Macaskill, A. (2007). Personality, Individual Differences and Intelligence (1st ed.). Harlow: Pearson Prentice Hall.

Parnicky, E., Williams, M., \& Silva, W., (1987); Surveying the Relationship between Locus ofControl and Academic Performance, Journal of Social and Clinical Psychology 7 (2-3): 97-100.

Jahanbakhsh, Rahmani. "Learning Styles and Academic Performance: a Case Study of Iranian High School Girl's Students", Procedia Social and Behavioral Sciences, 2012.

Roddenberry, Angela; Renk, Kimberly. "Locus of Control and Self-Efficacy: Potential Mediators of Stress, Illness, and Utilization of Health Services in College Students". Child Psychiatry \& Human Development 41 (4): 353-370.

Rotter, J.B (1975). Some problems and misconceptions related to the construct of internal versus external control of reinforcemen. Journal of Consulting and Clinical Psychology, 43, 56-67.

Rotter, J.B. (1966). Generalized expectancies for internal versus external control of reinforcement. Psychological Monographs, 33 (1), 300-303.

Rotter, J.B. (1975). "Some problems and misconceptions related to the construct of internal versus external control of reinforcement". Journal of Consulting and Clinical Psychology 43: 56-67.

Rotter, J.B. (1990). "Internal versus external control of reinforcement: A case history of a variable" (PDF). American Psychologist 45 (4): 489-93.

Sandler, I., N., \& Lakey, B., (1989) Locus of control as a stress moderator: The role of control perceptions and social support. American Journal of Community Psychology, Volume 10, Number 1, pg 234-256.

Schultz, D.P., Schultz, S.E. (2005). Theories of Personality (8th ed.). Wadsworth: Thomson.

Shepherd, S., Owen, D, Fitch, TJ, Marshall, JL, (2006) Locus of control and academic performance in high school students, Psychol Rep. April 98 (2): 318-22.

Stahl, S. A. (2002). Different strokes for different folks? In L. Abbeduto (Ed.), Taking sides: Clashing on controversial issues in educational psychology (pp. 98-107). Guilford, CT, USA: McGraw-Hill.

VanderZee, K., I., "Social Support, Locus of Control, and Psychological Well-Being", Journal of Applied Social Psychology, 10/1997

Xenikou, A.; Furnham, A., McCarrey, M. (1997). "Attributional style for negative events: A proposition for a more valid and reliable measaure of attributional style". British Journal of Psychology 88: 53-69.

\section{Websites}

www.jasonswrench.com

www.answerparty.com

www.google.co.uk

www.ittralee.ie

www.answers.com

www.uir.unisa.ac.za

www.oppapers.com

www.ipedr.net 